\title{
Coping strategies as predictors of coursework stress among university nursing students
}

\author{
Salwa Eweis Hassanein ${ }^{* 1}$, Inass Helmy Elshair ${ }^{2}$, Amany Ahmed Abdrbo ${ }^{2}$, Eman Gaber Hassan ${ }^{3}$ \\ ${ }^{1}$ Community Health Nursing Department, Faculty of Nursing, Cairo University, Cairo City, Egypt \\ ${ }^{2}$ Nursing Administration Department, Faculty of Nursing, Cairo University, Cairo City, Egypt \\ ${ }^{3}$ Medical Surgical Nursing Department, Faculty of Nursing, Cairo University, Cairo City, Egypt
}

Received: May 31, 2016

DOI: $10.5430 /$ jnep.v7n2p99
Accepted: August 23, $2016 \quad$ Online Published: October 8, 2016

URL: http://dx.doi.org/10.5430/jnep.v7n2p99

\begin{abstract}
For nursing students, coping with stress is a dynamic and continuous process. Students are affected by different kinds of stressors such as the pressure to achieve academically. It is important for students to develop coping strategies in order to succeed. The aims of this study are assessing nursing students' perceived level of university coursework stress and their coping strategies, describing the difference between male and female nursing students in that respect, and identifying coping strategies that can predict coursework stress levels. A descriptive, predictive study was conducted utilizing a sample of 96 nursing students. The participants were asked to fill a self-administered questionnaire about coping strategies. The conclusion of this study is that nursing students have moderate stress levels related to their academic coursework. Problem-solving strategies have the highest mean of the eight subscales; however, wishful thinking and tension reduction were the only significant coping mechanisms that worked as predictors of coursework stress.
\end{abstract}

Key Words: Stress, Coping strategies, Nursing students

\section{INTRODUCTION}

During the 20th century, there was a vast rise in the dynamic transactional relationship between a person and his/her environment, which has been viewed as stress for that, and the stress was considered as the disease of the century. ${ }^{[1]}$ Previous studies defined stress as the person's reaction to an event in the world, which he/she might perceive as a possible threat. ${ }^{[2,3]}$ The event or the stressor could be anything like environmental stressors, a change in daily lifestyle, a daily stress event, workplace stress, and social stress.

Academic work is considered as a stressor among students due to the nature of college life. ${ }^{[4]}$ Which includes stressful factors such as tuition fees, courses exams, homework required at the same due dates, project time limits, time man- agement needed, unclear assignments, looking for course references and uncomfortable classrooms, as well as not enough leisure time. ${ }^{[5,6]}$ Additionally, unforeseeable evaluation criteria, and the nonexistence of teaching staff in office hours was a source of stress. ${ }^{[7]}$ Finally, concerns regarding the students' future careers that cause academic pressure to get good grades and keeping up with academic stands of the university for further study or professional careers. ${ }^{[8]}$

Nursing students have the same academic stressors as other college students, such as examinations, course papers, and assignments. ${ }^{[9]}$ In addition, nursing students feel uncertainty, fear making mistakes, lack self-confidence, and have poor relationships with educators. ${ }^{[5,10]}$ Moreover, the nursing courses include clinical experiences, which are highly

*Correspondence: Salwa Eweis Hassanein; Email: salwa.hassanein@ yahoo.com; Address: Faculty of Nursing, Cairo University, Cairo City, Egypt. 
stressful due to the students' unfamiliarity with clinical settings, ${ }^{[10,11]}$ and handling highly technical equipment. ${ }^{[9,12]}$ In clinical settings, nursing students must perform cautiously, or else, they will cause serious harm to the patients, causing their fear of making mistakes. Earlier studies ${ }^{[13]}$ pointed to the stress caused by their responsibility for providing care and dealing with a sick person in addition to the painful experiences of death cases.

To date, few studies have assessed the stress of students in Egypt or other Arabic countries, and most of them deal with medical students. For example, a systematic review was done from January 1998, to October 2009, among Arab medical students. The study found a high prevalence of perceived stress among medical students, which result was similar to those reported in the international literature. ${ }^{[14]}$ The prevalence of high stress was nearly equal in male medical students in Egypt and Saudi Arabia. ${ }^{[15]}$ They found that students from Egypt reported more academic and environmental stressors than Saudi students. ${ }^{[15]}$ The only study conducted in Egypt (in Mansoura) with baccalaureate nursing students sought to assess their perceived stress, and it revealed that academic pressures were the most frequent stressors among nursing students. ${ }^{[16]}$ Regionally, in Saudi Arabia, Eswi, Radi, and Youssr $^{[6]}$ reported that the highest stressors among baccalaureate Saudi nursing students were academic stressors (57\%) and the rest were environmental factors (43\%). Coping is adapting or dealing with stressful situations, which can be life, work, or family problems, among others.

\section{Theoretical framework}

Lazarus and Folkman's ${ }^{[17]}$ theory of coping was utilized as the theoretical framework for this study. Stress was explained as a relationship between an individual and his or her environment that is perceived as dangerous or considered beyond his or her ability to deal with threats. For that, the individual's perception and his emotional reaction are the causes of stress, not the event itself. In the current study, we hypothesized the individual coping strategy that predicted his or her level of stress. Lazarus and Folkman ${ }^{[17]}$ identified eight coping strategies believed to be used by individuals in stressful situations. These eight subscales include problemfocused coping, wishful thinking, detachment, seeking social interactions; focusing on the positive, self-blame, tension reduction, and keeping to oneself. These eight subscales separate into two types of coping strategies to change either the environment (problem-focused) or the meaning of the event (emotion-focused or palliative) directly. ${ }^{[18]}$ Problemfocused coping contains feelings, activities, and approaches geared toward eradicating or lessening a stressful event or its effect and tends to activate when an individual believes that something can be done to change his/her situation by determining the best strategy for dealing with the situation and putting it into action. Emotion-focused coping contains feelings, activities, and approaches directed toward the controlling and reduction of distressing emotions connected with a threatening event and is raised when an individual perceives that a stressor must be endured by using mainly the cognitive processes to reduce perceived suffering. ${ }^{[19]}$ They added that most individuals in response to stressful events use both an emotion and problem-focused form of coping. Sohail ${ }^{[20]}$ stated that problem-solving strategies might be a discussion with seniors and emotion-focused coping strategies such as walks, cooking, etc. Moreover, Internet chats and cell phone texting could be used as an emotional coping strategy which often takes the form of escaping from real problems or as a problem-solving coping strategy when discussing with friends to get the benefit from their experiences. ${ }^{[20]}$

Lees and Ellis ${ }^{[13]}$ reported that coping strategies depended on experience, and the students depend more on emotionalfocused ways of coping while qualified staff showed more use of problem-focused approaches to deal with stressful situations. Pulido-Martos Augusto-Landa and Lopez-Zafra, ${ }^{[12]}$ noted that the courses and the academic year which the nursing students are enrolled in might influence the coping strategies that they would select while they deal with stress. More specifically, second-year student nurses found to be using emotionally focused strategies (avoidance) as coping strategies more than senior nurses or students who are registered in advanced adult nursing courses.

Previous studies indicated that in the long term or in high levels of stress if the students fail to resolve their stress it might be lead to physiological, psychological and mental health-related problem, in addition to serious professional and personal problems. ${ }^{[5,21]}$

Stress among nursing students could have significant negative and positive consequences on their thinking and learning. ${ }^{[5,22]}$ Another study reported that a high level of stress might have a negative effect on the cognitive functioning and learning of students in medical school. ${ }^{[23]}$ However, insufficient data were available about stress and coping strategies' effects on academic performance among Arab students. ${ }^{[14]}$ Therefore, the objectives of the present study are as follow: Assess nursing students' perceived levels of university coursework stress and their coping strategies related to their perceived stress. Describe the difference between the perceived level of university coursework stress and the coping strategies related to their perceived stress between male and female nursing students. Identify which coping strategy predicts the course work stress among nursing students (see 
Figure 1).

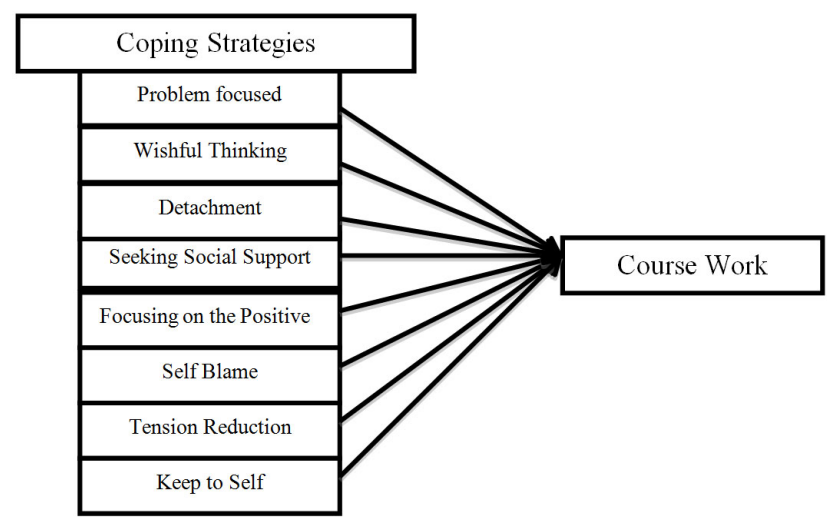

Figure 1. Coping Strategy Model

\section{MeTHOD}

\subsection{Design and setting}

A descriptive correlational cross-sectional predictive design was used to collect data at the college of nursing at Cairo University. This design was used to describe the study variables and find out which coping strategies could predict coursework stress levels.

\subsection{Sampling and ethical considerations}

Ninety-six undergraduate nursing students were recruited in the academic year 2011/2012, ranging from first- to fourthyear students enrolled in the four-year nursing program. The participants were asked to fill out a self-administered questionnaire and hand it in to the researchers. Accompanying each questionnaire was a cover letter explaining the purpose of the study, assuring anonymity and giving instructions regarding what to do with the survey once it had been completed. The ethical approval was granted by administrative authorities of the Faculty of Nursing and the university. The aim of the study was explained to the nursing students. Moreover, participation was voluntary, and the questionnaire was anonymous. The data were kept confidential. Identification numbers were used to enter them into a computer.

\subsection{Instruments}

A demographic data sheet was used to collect data about the students' age, gender, and current year of study, marital status, and courses being taken.

The revisedways of coping strategies questionnaire consisted of 42 items. ${ }^{[24]}$ The questionnaire contained thoughts and actions that people do to deal with internal and/or external stress. The response format ranged from 0 (not used), 1 (used somewhat), 2 (used quite a bit), and 3 (used a great deal) with 8 subscales. The eight subscales including problem-focused coping (11 items), wishful thinking (5 items), detachment
(6 items), seeking social support (7 items), focusing on the positive ( 4 items), self-blame ( 3 items), tension reduction (3 items), and keeping to oneself ( 3 items). The questionnaire was used among undergraduate college students in previous studies and indicated valid (academic stress was significantly associated with problem-focused [B $=.19, p<.01]$, wishful thinking $[\mathrm{B}=.40, p<.001]$, seeking social support $[\mathrm{B}=$ $.24, p<.01]$, tension reduction $[\mathrm{B}=.26, p<.001]$, tension reduction $[\mathrm{B}=.23, p<.001]$, keeping to oneself $[\mathrm{B}=.36, p$ $<.001]$ ) and reliable results (the cronbach's alphas were .80 , $.76, .64, .68, .70, .52, .46$ and .56 respectively). ${ }^{[25,26]}$ The Cronbach's alphas in this study for the 8 subscales were .99 , $.86, .74, .82, .82, .76, .59$, and .65 , respectively.

The coursework stress scale has 11 items $^{[27]}$ related to the coursework; the mean score was calculated, and a higher mean score indicated higher coursework stress. The Likert scale was used to respond to the questionnaire with statements ranging from 0 (strongly disagree) to 4 (Strongly Agree). The Cronbach's alpha reported in this study was .88 .

\subsection{Statistical analyses}

Descriptive statistics include means and standard deviation for continuous variables, and numbers and percentages for categorical variables were used to explain the students' characteristics, their coursework stress, and their coping strategies. The differences in coping strategies for males and females were analyzed using independent sample $t$-tests. The ANOVA test was used to measure the differences among groups by the year of the study for bothcoping strategies, and coursework stress. The relationships between coping strategies and course work stress were analyzed by regression analysis. The significance level was set at 0.05 . Missing data was assessed and managed by replacing the mean score.

\section{ReSults}

The mean age of the students was $20.5 \pm 1.27$ and $50 \%$ were female $(\mathrm{N}=47)$. The majority of the students, were in the fourth year ( $N=47,49.5 \%)$ (see Figure 2) and about 93\% ( $N$ $=86$ ) of the students were single. However, only $50 \%$ of the students responded to this question, and $40 \%$ were studying community nursing ( $\mathrm{N}=20)$ (see Figure 3 ).

The mean scores showed that for all students the most to least commonly used coping strategies as following problemfocused coping (19.19 \pm 7.30$)$, seeking social support (12.22 $\pm 3.44)$, detachment $(9.77 \pm 3.99)$, wishful thinking $(8.49 \pm$ $2.58)$, focusing on the positive $(6.52 \pm 2.12)$, tension reduction $(5.03 \pm 2.10)$, self-blame (4.92 \pm 1.96$)$, and keeping to self $(4.83 \pm 2.81)$. The students' course work stress mean score was $2.09 \pm 0.75$ on a scale ranging from 0 to 4 . 


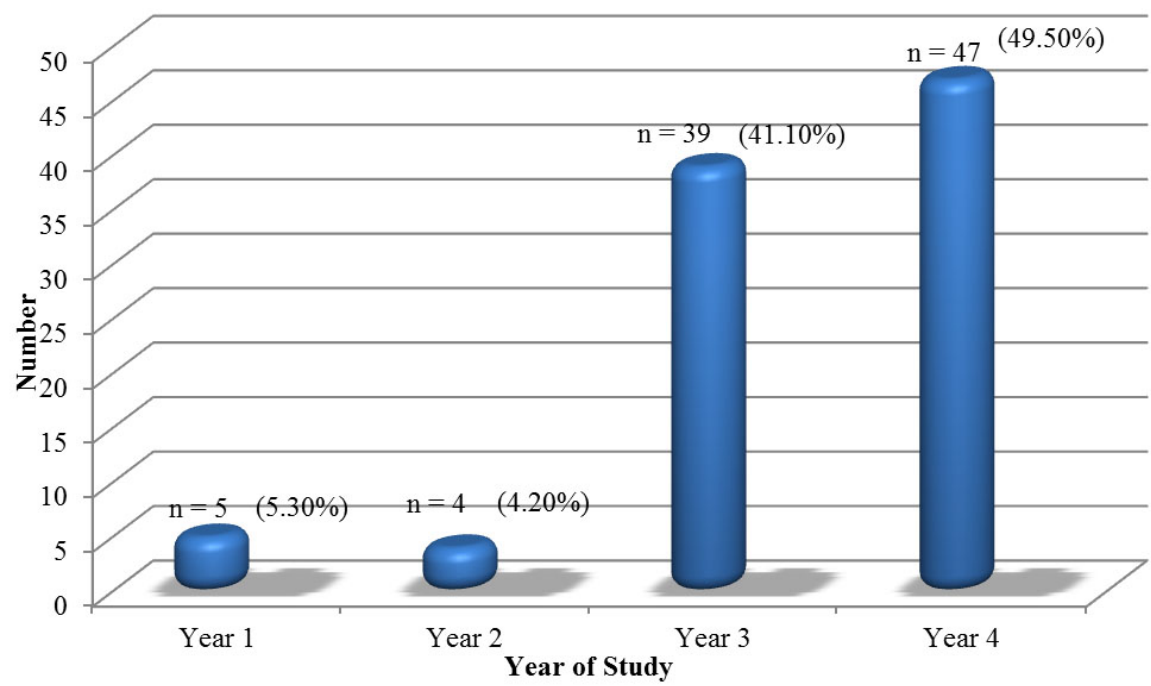

Number and

Percentage of

Students in each Year

Figure 2. Year of Study $(\mathrm{N}=95)$

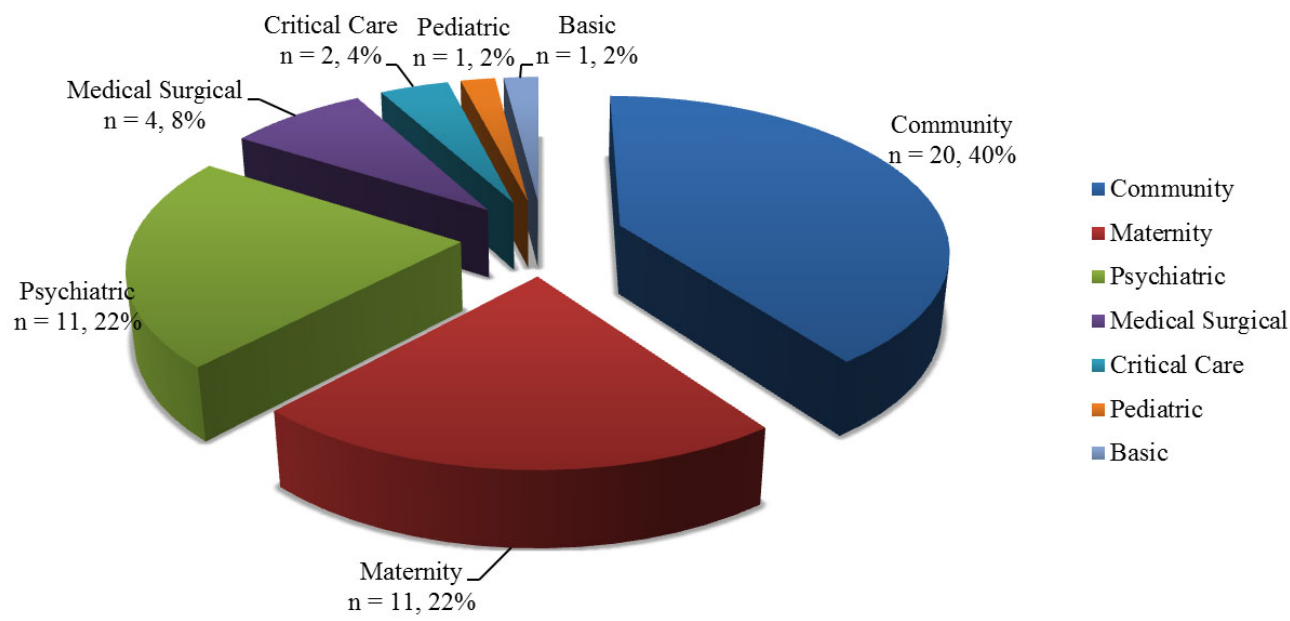

Figure 3. Numbers and Percentages of students' Nursing Courses Taken $(\mathrm{N}=50)$

ANOVA tests for coping strategies and course work stress among students by year of the study indicated that there were no significant differences among groups except for problem focused $(\mathrm{F}=3.61, p=.02)$ (see Table 1); it was higher for students in year 1 followed by students in year 2 .

The $t$-test (see Table 2) indicated that only significant difference between male $(11.26 \pm 2.96)$ and female students $(13.23 \pm 3.68)$ was regarding seeking social support $(t=$ $2.84, p=.005)$ whereas female students tend to seek social support more than male students. There were no significant differences among male $(2.03 \pm 0.94)$ and female students $(2.16 \pm 0.49)$ related to coursework stress $(t=0.81, p=.41)$

Regression analysis revealed that wishful thinking (Beta $=0.27 ; p=.01)$ and tension reduction (Beta $=0.35 ; p<$ $.001)$ coping strategies were the only significant predictors of coursework stress from the 8 coping strategies subscales.
The regression analysis also indicated that the model was significant $(\mathrm{F}=3.92 ; p=.001)$, and the independent variables (coping strategies) explain $27 \%$ of the course work stress (see Table 3).

\section{Discussion AND CONCLUSION}

The results revealed that the students' coursework stress was moderate. These results are consistent with those of Eswi, Radi, and Youssr, ${ }^{[6]}$ who reported a moderate-to-high level of perceived stress among Saudi and Jordanian nursing students in their first weeks of clinical practice. ${ }^{[11]}$ Similarly, Papazisis, Vlasiadis, Papanikolaou, Tsiga, and Sapountzi-Krepia ${ }^{[28]}$ reported that $71.8 \%$ of nursing students in Greece reported having mild levels of stress. Other studies dealing with students enrolled in other subjects in college also reported they had moderate levels of stress. ${ }^{[29,30]}$ 
Table 1. Descriptive statistics and ANOVA tests for coping strategies and course work stress among students by year of study

\begin{tabular}{lllllll}
\hline Variables & Year 1 & Year 2 & Year 3 & Year 4 & F & p-Value \\
\hline $\mathrm{n}(\%)$ & $5(5.3 \%)$ & $4(4.2 \%)$ & $39(41.1 \%)$ & $47(49.5 \%)$ \\
\hline \multicolumn{7}{c}{ Coping Mechanisms [Mean (SD)] } \\
\hline Problem Focused & $27.09(15.13)$ & $24.83(10.68)$ & $17.62(4.37)$ & $19.30(7.39)$ & 3.61 & .02 \\
Wishful Thinking & $9.73(1.918)$ & $9.00(2.94)$ & $8.06(2.69)$ & $8.75(2.49)$ & 0.94 & .42 \\
Detachment & $11.48(5.92)$ & $10.14(1.01)$ & $9.15(2.95)$ & $10.13(4.64)$ & 0.74 & .52 \\
Seeking Social Support & $13.89(1.44)$ & $10.75(2.50)$ & $11.45(2.75)$ & $12.96(3.87)$ & 2.14 & .10 \\
Focusing on the Positive & $6.80(1.64)$ & $6.41(1.89)$ & $6.39(2.10)$ & $6.60(2.27)$ & 0.09 & .96 \\
Self Blame & $5.54(2.48)$ & $5.25(1.89)$ & $4.79(1.70)$ & $4.98(2.15)$ & 0.26 & .85 \\
Tension Reduction & $5.96(3.09)$ & $6.50(1.73)$ & $4.53(2.11)$ & $5.23(1.97)$ & 1.86 & .14 \\
Keep to Self & $4.62(1.12)$ & $5.91(2.63)$ & $4.32(2.02)$ & $5.21(3.43)$ & 0.91 & .43 \\
Course work Stress & $2.34(.44)$ & $2.40(1.21)$ & $1.95(.71)$ & $2.17(.75)$ & 1.04 & .37 \\
\hline
\end{tabular}

Table 2. Gender differences regarding coping strategies and course work stress

\begin{tabular}{lllll}
\hline Variables & Male $(\mathbf{N}=\mathbf{4 7})$ & Female $\mathbf{( N = 4 7 )}$ & $\boldsymbol{t}$-test & $\boldsymbol{p}$-Value \\
\hline Problem Focused & $18.08(6.14)$ & $20.37(8.31)$ & 1.52 & .13 \\
Wishful Thinking & $8.42(2.71)$ & $8.52(2.50)$ & 0.18 & .85 \\
Detachment & $9.86(4.53)$ & $9.62(3.44)$ & -0.29 & .77 \\
Seeking Social Support & $11.26(2.96)$ & $13.23(3.68)$ & 2.84 & .005 \\
Focusing on the Positive & $6.47(1.94)$ & $6.67(2.28)$ & 0.45 & .65 \\
Self Blame & $4.81(1.85)$ & $5.14(2.04)$ & 0.80 & .42 \\
Tension Reduction & $4.95(1.97)$ & $5.10(2.28)$ & 0.35 & .72 \\
Keep to Self & $4.96(3.52)$ & $4.76(1.91)$ & -0.34 & .73 \\
Course work Stress & $2.03(.94)$ & $2.16(.49)$ & 0.81 & .41 \\
\hline
\end{tabular}

Table 3. Regression analysis for coping strategies predicting course work stress

\begin{tabular}{lllll}
\hline Independent Variables & B & Beta & $\boldsymbol{t}$ & $\boldsymbol{p}$-Value \\
\hline Problem Focused & -0.01 & -0.11 & -0.93 & .35 \\
Wishful Thinking & 0.08 & 0.27 & 2.54 & .01 \\
Detachment & 0.03 & 0.19 & 1.64 & .10 \\
Seeking Social Support & 0.00 & 0.00 & 0.01 & .98 \\
Focusing on the Positive & 0.02 & 0.06 & 0.54 & .59 \\
Self Blame & -0.04 & -0.11 & -1.06 & .29 \\
Tension Reduction & 0.12 & 0.35 & 3.45 & .00 \\
Keep to Self & -0.01 & -0.06 & -0.68 & .49 \\
\hline
\end{tabular}

The severity of the stress students experience may vary according to their experiences and their academic level. The majority of the students in the current study were in their fourth year at college. Also, the first year in college might be considered more stressful due to transition from high school to university. This opinion is consistent with previous findings. Petal, Sudduth, and Jakopac ${ }^{[31]}$ and Stopper, Ross, and Chiang-Hanisko ${ }^{[32]}$ reported nursing students in their first course of the BSN program in the US experienced moderate- to-high levels of stress. It is not only familiarity with the academia that affects the students' stress levels but also special courses. Khater, Akhu-Zaheya, and Shaban ${ }^{[11]}$ found that stress levels were affected by the type of courses and the Adult Heath Nursing I Practicum Course, in particular, caused the highest stress to students.

In regard to coping strategies, the results showed that the most to least commonly used coping strategies among nurs- 
ing students was problem-focused coping, seeking social support, detachment, wishful thinking, focusing on the positive, tension reduction, self-blame, and keeping to self. This finding is in agreement with Sohail ${ }^{[20]}$ who found that students were using a mixture of coping strategies, such as problemand emotion-focused strategies. However, Kumar ${ }^{[33]}$ found that the most to least commonly used coping strategies were seeking diversion, solving family problems, developing social support, self-reliance, ventilating feelings, engaging in demanding activities, avoiding, relaxing, searching for spiritual support, being humorous, ventilating his feeling to close friends, and asking for professional help. The different coping strategies commonly used by students in previous research might be due to differences in age, gender, type of study, and culture. WHO/EHA ${ }^{[34]}$ guidelines have indicated that there are no standards for coping strategies and they vary depending on the socio-cultural, individual's previous experiences, age, gender, household, social group, region, community, season, and time.

The current study's results are in agreement with the finding of previous studies in the last 20 years, Evans and Kelly ${ }^{[3]}$ stated that talking to relatives and friends and talking to peers were the most common methods of coping with stress among pre-registration diploma nursing students in Ireland. Moreover, Chiang, Hunter, and $\mathrm{Yeh}^{[35]}$ also mentioned that the most frequently reported coping strategies among Black and Latino college students were talking with parents, talking with friends, and doing social and religious activities. Additionally, Seyedfatemi, Tafreshi, and Hagani ${ }^{[5]}$ studied the coping strategies of nursing students in 12 areas in Iran and found that most of them $(64.5 \%)$ used their families' problem-solving strategies, which meant "trying to reason with parents and compromise" and "going along with family rules". Furthermore, Murdock, Naber, and Perlow ${ }^{[36]}$ noted that almost half of the surveyed baccalaureate nursing students did not feel they used good stress management skills and they reported eating, exercising, listening to music, socializing, smoking, doing meditation/deep breathing, and drinking alcohol as ways to alleviate their stress.

$\operatorname{Kumar}^{[33]}$ assessed the stress levels and coping strategies of nursing students. He reported that the majority of nursing students tend to use healthy coping strategies. The most common coping strategy was "seeking diversion" and the least common was "seeking professional support". Khater, Akhu-Zaheya, and Shaban ${ }^{[37]}$ also found that the coping behaviors held in esteem were being optimistic, having a positive attitude when dealing with everyday issues in life, employing past experiences to solve problems, looking at things objectively, identifying objectives, and implementing different approaches to solve problems. The interpretation of the differences between the results of the studies could be clarified if we look at social support and talking to relatives or friends as both problem-focused and emotional-focused coping strategies. If the students talk to others to get solutions for their stress, this strategy could possibly be set as problem-solving.

The results also revealed that there were no significant differences among male and female students in relation to the coursework stress. Few old studies supported the current research finding. From Egypt, Amr, El-Gilany, and ElHawary ${ }^{[38]}$ reported that Egyptian female students scored higher than males on the depression and neuroticism scales while Egyptian male and female medical students were similar in their levels of perceived stress, clinical anxiety, and a number of stressors, physical well-being factors, and the extraversion scale. Also, Clarke and Ruffin ${ }^{[39]}$ found that the main sources of stress were essentially the same for female and male student nurses. On the contrary, different studies done in the Middle East reported that female students were prone to having more stress than males in Saudi Arabia, Emirate, Jourdain, and Pakistan. ${ }^{[4,30,40-42]}$

As shown, studies reported opposing results regarding gender. Some researchers reported that female students perceive higher stress than male students did, and other researchers reported that there is no difference in the level of stress perceived by both genders. The differences between the results of this study and previous studies could be interpreted in relation to the differences in culture, where the females in Saudi Arabia, Arab Emirate, and Pakistan were probably married during their college years. Married female students experienced a high level of stress during their college years due to more responsibilities being required of them as wives and mothers in addition to their required coursework. Additional, the females in Saudi Arabia are not involved in outdoor activities like males.

Another reason might be the social changes in Egypt where the female students have been used to the stress of education since they were in high school. They are obligated to get higher marks in high schools to be accepted into the public universities. In addition, it was noticed recently that the top ten students were mostly female during the latest year, as mentioned on the Egypt Ministry of Education website in 2014. Furthermore, the lack of differences between the genders in the study sample may be due to the homogenous nature of the students with exclusive personal characteristics needed for the competitive environment of the nursing school.

In the current study, the regression analysis revealed that wishful thinking and tension reduction coping strategies 
(emotional-focused strategy) were the only significant predictors of coursework stress from the eight coping strategy subscales, and the models were significant. If the students do not deal with their stressors successfully it might be lead to health problem. ${ }^{[5,21]}$ For that, tension reduction could predict perceived coursework stress among students. In the same line, Gloria, Castellanos, Scull, and Villegas ${ }^{[43]}$ reported that cultural congruity and emotion-focused coping were most predictive of psychological well-being among male Latino undergraduates. Similarly, Roy ${ }^{[27]}$ stated that problem strategies had no relationship to coursework stress but that wishful thinking and anxiety were both positive predictors of stress.

\section{IMPLICATIONS AND RECOMMENDATIONS}

Our findings may be helpful for clinical educators and faculty members to identify and understand students' levels of stress and patterns of students' coping strategies. This could be significant in promoting a healthy, supportive learning environment. Consequently, decreasing unnecessary assignments and the workload for nursing students is needed in order to build a motivating clinic that has been of great benefit to students on their academic and personal lives. Moreover, faculty members and clinical instructors should spend more time to build a rapport-based relationship with their students to be able to understand their personalities and to identify the areas that lead to more stress and set strategies to decrease it, which might be achieved through academic advising.

Furthermore, the curriculum should be revised and add stress management training as extra-curriculum activities or as elective courses for students in order to train them with ways and means of reducing their stress levels from the first year of joining the college. Finally, there is a need to apply more approaches to decrease stress among students, like increase healthier interaction with the faculty, extra freedom-time activities, appropriate advising, counseling and guidance facilities, and peer-counseling at the college

It is recommended to replicate the study on different colleges and different academic level on a comprehensive longitudinal approach to explore the impact of other curricular and educational environmental factors on student stress. Exploring the coping strategies by using different designs, such as qualitative studies, will help to collect data about students' experiences for profound insight and deep analysis of these feelings. There is a need to examine how the nursing students in the Arab-Islamic culture utilize spirituality and religious as a positive moderator for coping. Furthermore, there is another point that has not been explored yet-the relationship between nursing students' stress and their perceived social support from teachers, family, and friends. In Arab countries, children are more dependent until they graduate, so there is a need to explore how nursing students have higher levels of healthy self-reliance in dealing with stress than students in other countries do.

\section{Limitations}

Although the study provided some useful and interesting data, several limitations should be noted such as the sampling technique and design. The convenient sample was selected from one nursing institution; this limited the generalizability of the results. Also, collecting data about stress at one point in time although stress varies at different times. Low sample size affected the number in each subgroup; this limited the comparisons in the statistical analysis. In addition, the students might have been affected by the social desirability bias in their answers to look better than they were.

\section{Conflicts of InTEREST Disclosure}

The authors declare that there is no conflict of interest.

\section{REFERENCES}

[1] Dahlin M, Joneborg N, Runeson B. Stress and depression among medical students: a cross-sectional study. Med Educ Medical Education. 2005; 39(6): 594-604. PMid:15910436 http://dx. doi .org $/ 10.1111 / j .1365-2929.2005 .02176 . x$

[2] Thompson J. Stress theory and therapeutic practice. Stress Medicine. 1992; 8(3): 147-150. http://dx.doi.org/10.1002/smi. 24600 80303

[3] Evans W, Kelly B. Pre-registration diploma student nurse stress and coping measures. Nurse Education Today. 2004; 24(6): 473482. PMid:15312957 http://dx. doi .org/10.1016/j.nedt. 20 04.05 .004

[4] Hamaideh SH. Stressors and reactions to stressors among university students. International Journal of Social Psychiatry. 2009.
[5] Seyedfatemi N, Tafreshi M, Hagani H. Experienced stressors and coping strategies among Iranian nursing students. BMC Nursing. 2007; 6(1): 11. PMid:17999772 http://dx.doi.org/10.1186/1 472-6955-6-11

[6] Eswi AS, Radi S, Youssri H. Stress/stressors as perceived by baccalaureate Saudi nursing students. Middle East J. Sci. Res. Middle East Journal of Scientific Research. 2013; 14(2): 193-202.

[7] Alawad AA, Slamah AA. The prevalence of stress among interior design and furniture students. European Scientific Journal. 2014; $10(23)$.

[8] Pandya BU, Deshpande RC, Karani A. A Study on Impact of Academic Stress on MBA Students of Gujarat Technological University. Researcher's World-Journal of Arts, Science and Commerce. 2012; 3(3).

[9] AL-BARRAK MY, EL-NADY MT, FAYAD EA. Sources of stress as 
perceived by nursing students at King Saud University. The Medical Journal of Cairo University. 2011; 79(2).

[10] Sendir M, Acaroglu R. Reliability and validity of Turkish version of clinical stress questionnaire. Nurse Education Today. 2008; 28(6): 737-743. PMid: 18164787 http://dx.doi.org/10.1016/j.ned t. 2007.11 .008

[11] Shaban IA, Khater WA, Akhu-Zaheya LM. Undergraduate nursing students' stress sources and coping behaviours during their initial period of clinical training: A Jordanian perspective. Nurse Education in Practice. 2012; 12(4): 204-209. PMid:22281123 http: //dx.doi.org/10.1016/j.nepr.2012.01.005

[12] Pulido-Martos M, Augusto-Landa JM, Lopez-Zafra E. Sources of stress in nursing students: a systematic review of quantitative studies. INR International Nursing Review. 2012; 59(1): 15-25. http://dx.doi.org/10.1111/j.1466-7657.2011.00939.x

[13] Lees S, Ellis N. The design of a stress-management programme for nursing personnel. Journal of Advanced Nursing. 1990; 15(8): 94661. PMid:2229692 http://dx.doi.org/10.1111/j.1365-264 8.1990.tb01951.x

[14] Elzubeir M, Elzubeir K, Magzoub M. Stress and coping strategies among Arab medical students: towards a research agenda. Education for Health. 2010; 23(1): 355.

[15] El-Gilany AH, Amr M, Hammad S. Perceived stress among male medical students in Egypt and Saudi Arabia: effect of sociodemographic factors. Annals of Saudi Medicine. 2008; 28(6). PMid:19011321 http://dx.doi.org/10.4103/0256-4947.51 666

[16] Amr A, et al. Stress among Mansoura (Egypt) baccalaureate nursing students. Pan African Medical Journal. 2011; 8(1). http://dx.doi .org/10.4314/pamj.v8i1.71083

[17] Lazarus RS, Folkman S. Stress, appraisal, and coping. New York: Springer Pub. Co.; 1984

[18] Folkman S, Lazarus RS. Ways of coping questionnaire. Consulting Psychologists Press; 1988.

[19] Folkman S, Lazarus R. An analysis of coping in a middle-aged community sample. Kango kenkyu. The Japanese Journal of Nursing Research. 1988; 21(4): 337. PMid:3210434

[20] Sohail N. Stress and academic performance among medical students. Journal of the College of Physicians and Surgeons-Pakistan: JCPSP 2013; 23(1): 67-71. PMid:23286627

[21] Sarafino EP. Health psychology: biopsychosocial interactions. Hoboken, N.J.; Chichester: Wiley; John Wiley [distributor]. 2011.

[22] Gibbons C, Dempster M, Moutray M. Stress and eustress in nursing students. Journal of Advanced Nursing. 2008; 61(3): 282290. PMid:18197862 http://dx.doi.org/10.1111/j.1365-2 $648.2007 .04497 . \mathrm{x}$

[23] Abdulghani HM, et al. Stress and its effects on medical students: a cross-sectional study at a college of medicine in Saudi Arabia. Journal of Health, Population, and Nutrition. 2011; 29(5): 516-22. http://dx.doi.org/10.3329/jhpn.v29i5.8906

[24] Folkman S, Lazarus RS. If it changes it must be a process: study of emotion and coping during three stages of a college examination. Journal of Personality and Social Psychology. 1985; 48(1): 150. PMid:2980281 http://dx.doi .org/10.1037/0022-3514. 48.1 .150

[25] Folkman S, Lazarus RS. Manual for the ways of coping questionnaire. Consulting Psychologists Press; 1988.

[26] Chan AMC. Academic stress and health outcomes among college students: A comparative study in Hong Kong and mainland Chinese students. 2009.
[27] Roy A. Coursework stress in university students: Investigating problem solving coping, wishful thinking coping, anxiety and depression as predictors of coursework stress. United Kingdom (UK). 2003.

[28] Papazisis G, et al. Depression and anxiety among nursing students in Greece. Annals of General Psychiatry. 2008; 7(1): 1 http://dx.doi.org/10.1186/1744-859x-7-s1-s209

[29] Bataineh MZ. Academic stress among undergraduate students: the case of education faculty at King Saud University. International Interdisciplinary Journal of Education. 2013; 2(1): 82-88. http: //dx.doi.org/10.12816/0002919

[30] Thawabieh AM, Qaisy LM. Assessing stress among university students. American International Journal of Contemporary Research. 2012; 2(2): 110-116.

[31] Patel S, Sudduth A, Jakopac K. Self-reported life stressors among students in their first nursing course. in Proceedings of the 16th International Nursing Research Congress Sigma Theta Tau International (Proceedings made available in the Virginia Henderson Sigma Theta Tau Library). 2005.

[32] Stopper C, et al. School and Personal Stressors Among Baccalaureate Nursing Students in Taiwan. Midwest Nursing Research Society Conference. 2010.

[33] Nancy R. Stress and coping strategies among nursing students. Nurs Midwifery Res J. 2011; 7: 141-51.

[34] WHO/EHA. Overview coping mechanisms in emergency health. Training programme for Africa. Panafrican Emergency Training Centre. 1999: 3-13.

[35] Chiang L, Hunter CD, Yeh CJ. Coping attitudes, sources, and practices among Black and Latino college students. Adolescence. 2004; 39(156): 793-815. PMid: 15727415

[36] Murdock C, Naber J, Perlow M. Stress level and stress management skills of admitted baccalaureate nursing students. Kentucky Nurse. 2010; 58(2).

[37] Khater W, Akhu-Zaheya L, Shaban I. Sources of stress and coping behaviours in clinical practice among baccalaureate nursing students. International Journal of Humanities and Social Science. 2014; 4(6): 194-202.

[38] Amr M, Hady El Gilany A, El-Hawary A. Does gender predict medical students' stress in Mansoura, Egypt? Medical Education Online. 2008. 13.

[39] Clarke VA, Ruffin CL. Perceived sources of stress among student nurses. Contemporary Nurse. 1992; 1(1): 35-40. PMid:1596613

[40] Al-Sowygh ZH. Academic distress, perceived stress and coping strategies among dental students in Saudi ArabiaAcademic distress and coping strategies among Saudi Arabian dental students. SDENTJ The Saudi Dental Journal. 2013; 25(3): 97-105. PMid:24179318 http://dx.doi.org/10.1016/j.sdentj.2013.05.002

[41] Abdulghani HM, et al. Stress and its effects on medical students: a cross-sectional study at a college of medicine in Saudi Arabia. Journal of Health, Population and Nutrition. 2011; 516-522. http://dx.doi.org/10.3329/jhpn.v29i5.8906

[42] Shah M, et al. Perceived stress, sources and severity of stress among medical undergraduates in a Pakistani medical school. BMC Medical Education. 2010; 10(1): 1. PMid:20078853 http://dx.doi.org /10.1186/1472-6920-10-2

[43] Gloria AM, et al. Psychological coping and well-being of male Latino undergraduates: Sobreviviendo la universidad. Hispanic Journal of Behavioral Sciences. 2009. http://dx.doi.org/10.1177/073 9986309336845 